\title{
Final Report For DOE Grant No. DE-FC02-01ER54650
}

\author{
Project Title: $\quad$ Numerical Computation of Wave-Plasma Interactions in \\ Multi-Dimensional Systems \\ Principal Investigator: $\quad$ Daniel A. D’Ippolito \\ Period Covered by Report: 8/1/2001 through 12/31/2004 \\ Date of Report: $\quad$ February 22, 2005 \\ Recipient Organization: Lodestar Research Corporation \\ 2400 Central Avenue \#P-5 \\ Boulder, CO 80301 \\ DOE Award No.: $\quad$ DE-FC02-01ER54650
}

\section{Background}

Our work under this contract and contributions to the "rf SciDAC project" in the years 2001 - 2004 covered three related areas of research:

a) developing a theory of rf-generated forces and sheared poloidal flow velocities in tokamak plasmas;

b) development of a wavelet diagnostic for the spatial dependence of the local kvectors of propagating rf waves;

c) an initial assessment of the formalism and computational methods for Parametric Decay Instability studies in inhomogeneous plasmas.

This final report summarizes briefly our work in each area and contains references to more detailed reports and publications. 


\section{Theory of rf-Generated Shear Flow}

There has been considerable interest in the possibility of employing rf waves, particularly in the ion cyclotron range of frequencies (ICRF), to induce shear in the poloidal flow velocity of tokamak plasmas. These sheared flows can be used to create internal transport barriers, thereby accessing high confinement regimes and greatly improving tokamak performance. The use of rf-driven shear flow also allows controlled fundamental physics studies of the interaction between flows and turbulence, a subject of general interest in many fields of physics.

In the first year, our work under this contract concentrated on developing and testing efficient nonlinear flow drive algorithms for post-processing the results of the AORSA wave propagation code. The nonlinear theory assumed variation only in the radial direction.

In the second and third years, the analysis was extended to two dimensions, motivated by recent numerical progress in the computation of two-dimensional full-wave field solutions for ICRF mode conversion scenarios, ${ }^{1}$ e.g. mode conversion from the fast wave (FW) to the ion Bernstein wave (IBW) or ion cyclotron wave (ICW). The gyrokinetic calculation of the rf-generated nonlinear forces was generalized to twodimensional (2D) rf fields. This calculation unified and generalized the different approaches taken by the Lodestar and ORNL groups for the 1D calculation in year one. The new approach shows that sheared flux-surface-averaged flows are driven by two classes of terms: direct absorption of wave momentum and dissipative stresses. Implementation of the 2D shear-flow formalism in the AORSA code yielded the important result that FW-IBW/ICW mode conversion scenarios relevant to C-Mod are expected to produce significant sheared flows. This work was presented in Refs. 2 and 3.

1. "Sheared Poloidal Flow Driven by Mode Conversion in Tokamak Plasmas," E. F. Jaeger, L. A. Berry, J. R. Myra, D. B. Batchelor, E. D’Azevedo, P. T. Bonoli, C. K. Phillips, D. N. Smithe, D. A. D’Ippolito, M. D. Carter, R. J. Dumont, J. C. Wright, and R. W. Harvey, Phys. Rev. Lett. 90, 195001-1 (2003).

2. "Momentum Conservation and Nonlinear RF-Induced Flows," J. R. Myra, D. A. D’Ippolito, E. F. Jaeger, L. A. Berry, and D. B. Batchelor, in Proceedings of 15th Topical Conference on Radio Frequency Power in Plasmas," (AIP, New York, 2003), p. 487; also available at http://www.lodestar.com/LRCreports/MomentumConservation.pdf .

3. "Nonlinear Fluxes and Forces from Radio-Frequency Waves with Application to Driven Flows in Tokamaks," J. R. Myra, L. A. Berry, D. A. D’Ippolito, and E. F. Jaeger, Phys. Plasmas 11, 1786 (2004); also available at http://www.lodestar.com/LRCreports/NonlinearFluxesForces.pdf . 


\section{Wavelet Analysis of rf Fields}

With the growing capability of rf simulations, there is a strong motivation to develop appropriate post-processing tools for extracting physical information from the numerical solutions. Full-wave ICRF codes yield complicated rf field patterns, and the challenge is to understand these patterns by appealing to the intuitive, but approximate, physics-based notion of local plasma modes (global eigenmodes, transmitted and reflected waves, and mode conversions between different types of waves). Quantitative information on the local wavevectors, amplitudes and wave polarizations is required for a basic understanding of the plasma heating and the ICRF-driven currents and flows. As part of the rf SciDAC project, numerical techniques (windowed Fourier transforms and wavelets) were investigated for the local mode analysis of ICRF field solutions.

In Ref. 1, 1D transform techniques were investigated for a DIII-D D(H) mode conversion reference case computed by the AORSA-1D code, which includes a model of the 2D poloidal magnetic field. It was shown that a "windowed Fourier transform" fails for multiple waves of vastly different wavelengths, such as occur in the mode-conversion problem, because the fixed window can only resolve one of the waves properly. The natural technique for solving this problem is a hybrid-transform which we constructed, called the "k-wavelet" transform ${ }^{1}$ which is essentially a Morlet wavelet modified to use a finite-width window near $\mathrm{k} \rightarrow 0$. The usefulness of this transform for diagnosis and visualization of rf field patterns with multiple waves on different scales was documented in Ref. 1 and a more complete discussion with illustrations in color is given in Ref. 2.

1. “Local Mode Analysis of 2D ICRF Wave Solutions,” D. A. D’Ippolito, J. R. Myra, E.F. Jaeger, L.A. Berry, D.B. Batchelor, in Proceedings of $15^{\text {th }}$ Topical Conference on Radio Frequency Power in Plasmas,” (AIP, New York, 2003), p. 463; also available at http://www.lodestar.com/LRCreports/kwavelets.pdf .

2. “Local Mode Analysis of 2D ICRF Wave Solutions,” D. A. D’Ippolito and J. R. Myra, Lodestar Report LRC-01-01 (2004), available at http://www.lodestar.com/LRCreports/LRC-04-101.pdf . 


\section{Analysis of Parametric Decay Instability}

In the course of our work on flow drive, it became apparent that other nonlinear effects could potentially be within reach of present day rf simulation codes with a modest level of effort and modifications to existing codes. One particularly interesting nonlinear effect is that of Parametric Decay Instability (PDI). PDI is a process by which large amplitude modes in the edge plasma decay into (usually) unwanted daughter waves by a nonlinear coupling mechanism. ${ }^{1}$ During the final months of our SciDAC grant we initiated exploratory studies into how the formalism developed for flow drive could be modified to treat PDI and what the implications might be for numerical implementation.

PDI equations generalize the conventional full wave solution to 3 coupled waves. Possibilities for carrying out either (i) a growth rate and threshold study, or (ii) a nonlinear saturated state computation, were identified. The derivation of the hot plasma coupling coefficients in a form suitable for AORSA implementation was found to be straightforward but tedious. These terms represent the (finite frequency) nonlinear beat current between two waves, and generalize the rf-driven flows which are closely related to the zero-frequency (quasilinear) beat current. Thus, similar formalism and implementation schemes apply as in the shear flow study. An estimate of computation work demonstrated that a general implementation would be very computationally intensive, and perhaps prohibitive in 2D, but the "dipole (long wavelength) pump wave" limit, of interest for many applications, is feasible, and in fact is equivalent in computational work to the flow drive analysis that has already been carried out.

1. M. Porkolab, Fusion Eng. Design 12, 93 (1990); and refs. therein.

2. R.C. Davidson, Methods in Nonlinear Plasma Theory (Academic, New York, 1972), Chapt. 6. 


\section{Lodestar Contributions to RF-SciDAC Publications}

\section{Refereed Journal Articles:}

Nonlinear Fluxes and Forces from Radio-frequency Waves with Application to Driven Flows in Tokamaks, J. R. Myra, L. A. Berry, D. A. D'Ippolito, and E. F. Jaeger, Phys. Plasmas 11, 1786 (2004).

Sheared Poloidal Flow Driven by Mode Conversion in Tokamak Plasmas, E. F. Jaeger, L. A. Berry, J. R. Myra, D. B. Batchelor, E. D'Azevedo, P. T. Bonoli, C.K. Phillips, D. N. Smithe, D. A. D'Ippolito, M. D. Carter, R. J. Dumont, J. C. Wright, R. W. Harvey, Phys. Rev. Lett., 90, 195001-1 (2003).

\section{Papers published in major conference proceedings:}

Mode Conversion Flow Drive in Tokamaks, E. F. Jaeger, L. A. Berry, J. R. Myra, D. B. Batchelor, and E. D'Azevedo, AIP Conf. Proc. 694, 475 (2003)

Momentum Conservation and Nonlinear RF-Induced Flows, J. R. Myra, D. A. D'Ippolito, L. A. Berry, E. F. Jaeger, and D. B. Batchelor, AIP Conf. Proc. 694, 487 (2003)

Local Mode Analysis of 2D ICRF Wave Solutions, D. A. D'Ippolito, J. R. Myra, E. F. Jaeger, L. A. Berry, and D. B. Batchelor, AIP Conf. Proc. 694, 463 (2003).

Tera-scale computation of wave-plasma interactions in multidimensional fusion plasmas, D. B. Batchelor, L. A. Berry, M. D. Carter, E. F. Jaeger, C. K. Phillips, R. Dumont, P. T. Bonoli, D. N. Smithe, R. W. Harvey, D. A. D'Ippolito, J. R. Myra, E. D'Azevedo, L. Gray, T. Kaplan, in Plasma Physics and Controlled Nuclear Fusion Research, 2002, Proceedings of the 19th International Conference, Lyon, France, (International Atomic Energy Agency, Vienna, 2002)

\section{Talks and Seminars:}

Advances in the Analysis of 2D RF-Driven Flows in Tokamaks, L. A. Berry, E. F. Jaeger, and J.R. Myra, presented at the 15th Topical Conference on Radio Frequency Power in Plasmas, Grand Teton National Park, Moran, WY (2003).

RF Flow Drive and Mode Conversion in Two Dimensions, Lee A. Berry in collaboration with Fred Jaeger (ORNL) and Jim Myra (Lodestar), presented at UCLA, April 7, 2003.

Linear Algebra Techniques for Solving Radio Frequency Electromagnetic Interaction Problems in Magnetized Plasmas, Lee A. Berry, Fred Jaeger, Ed D'Azevedo, Don Batchelor, Mark Carter, Steve Hirshman, Ben Carreras (ORNL), Cynthia Phillips (PPPL); Jim Myra, Dan D'Ippolito (Lodestar); David Smithe (Mission Research), Paul Bonoli, John Wright (MIT), presented at the SIAM Conference on Applied Linear Algebra, Williamsburg, VA, July 17, 2003

RF Flow Drive and Mode Conversion in Two Dimensions, Lee A. Berry in collaboration with Fred Jaeger (ORNL) and Jim Myra (Lodestar), presented at the University of Wisconsin, Madison, May 5, 2003 
Radio Frequency field Interactions in Magnetized Plasmas, Lee Berry, Fred Jaeger, Ed D'Azevedo, Don Batchelor, Mark Carter, Steve Hirshman, and Ben Carreras (ORNL), Cynthia Phillips (PPPL); Jim Myra, Dan D'Ippolito (Lodestar); David Smithe (Mission Research), Paul Bonoli, John Wright (MIT), presented at the 2003 SIAM Computational Science and Engineering Conference, San Diego, Feb. 10-13, 2003, Minisymposium on Plasma Physics and Computer Science: A Partnership for Advancing the understanding of Magnetically Confined Plasmas .

Nonlinear radio-frequency generation of sheared flows J.R. Myra in collaboration with D.A. D'Ippolito, (Lodestar) L.A. Berry, E.F. Jaeger, D.B. Batchelor (ORNL) and the Rf SciDAC Team, presented at the Transport Task Force Meeting, April 2-5, 2003, Madison, WI.

Nonlinear radio-frequency generation of sheared flows J.R. Myra in collaboration with D.A. D'Ippolito, (Lodestar) L.A. Berry, E.F. Jaeger, D.B. Batchelor (ORNL) and the Rf SciDAC Team, presented at the MIT/PSFC Spring Seminar Series, May 9, 2003, Cambridge, MA. 